\title{
Sanat Tarihine Geçmiş Eserlerin, Günümüz Sanatsal Tasarımlarına Etkilerinin Pastiş ve Parodi Kavramları Çerçevesinde Değerlendirilmesi
}

\author{
Turan VARDAR ${ }^{1}$ \\ ${ }^{1}$ Yüksek Lisans Öğrencisi, Necmettin Erbakan Üniversitesi, Güzel Sanatlar ve Mimarlık \\ Fakültesi, Resim Bölüm, Konya, Türkiye, vardar_turan@ hotmail.com \\ Mustafa KINIK ${ }^{2}$ \\ ${ }^{2}$ Doç. Dr. Necmettin Erbakan Üniversitesi, Güzel Sanatlar ve Mimarlık Fakültesi, \\ Grafik Bölüm, Konya, Türkiye, mkiniktf@gmail.com
}

\begin{tabular}{|c|c|}
\hline Makale Bilgileri & ÖZ \\
\hline $\begin{array}{l}\text { Makale Geçmişi } \\
\text { Geliş: 19.09.2021 } \\
\text { Kabul: } 12.11 .2021 \\
\text { Yayın: } 21.12 .2021 \\
\text { Anahtar } \\
\text { Kelimeler: } \\
\text { Pastiş, Parodi, } \\
\text { Resimsel Alıntılama, } \\
\text { Metinlerarasılık, } \\
\text { Sanatsal Tasarım, } \\
\text { Modern, Postmodern. }\end{array}$ & $\begin{array}{l}\text { Sanat tarihi incelendiğinde, insanların varoluşundan bu yana büyük bir etkileşim silsilesi } \\
\text { gözlenmektedir. İnsanlık, kendinden önceki toplumları doğrudan ya da dolaylı yollarla kendine ya da } \\
\text { kendi topluluklarına mal etmiştir. Antik dönemde üretilen sanat eserleri Rönesans dönemini, Rönesans } \\
\text { döneminde üretilen sanat eserleri de kendinden sonraki dönemlerin sanat eserlerini ve sanatçılarını } \\
\text { etkilemiştir. Günümüz sanatında, teknolojinin gelişmesi iletişimi daha da güçlü hale getirdi. Sanatsal } \\
\text { tasarımların, imgelerin aynı anda dünyaya yayılması etkileşimi arttırdı, pastiş ve parodinin gelişmesine } \\
\text { katkı sağladı. Pastiş (öykünme), sanat eserinin oluşum evresinde yer alan bir yöntem olarak } \\
\text { adlandırılır. Postmodern dönemde yer alan bir diğer yöntemde Parodi (yansılama)'dır. Pastiş yoluyla } \\
\text { üretilen eserler, sanatçıa saygı niteliğini taşırken, parodi yoluyla üretilen eserler alaycı ve mizah dolu } \\
\text { bir tavır sergilemektedir. Sanatçıya ve sanat eserine saygıyı gösteren pastiş, kendinden anlamca zıt } \\
\text { olan parodiyi doğurmuştur. Postmodern öğretinin belirleyici unsurlarından olan pastiş ve parodi bir } \\
\text { form olarak düşünüldüğünde, sanat dallarında bir alıntılama yöntemi olarak kullanılmaktadır. Eseri } \\
\text { üreten sanatçırar, kendilerinden sonraki sanatçılara esin kaynağı olmuş ve onlara bakış açıs } \\
\text { kazandırmışlardır. Sanata yeni arayış ve yorumlar getirerek anlam/kavramlar kazandıran bu } \\
\text { yöntemler, çoğunlukla postmodern dönemde karşımıza çıkmakta, yeniden üretilen eserleri anlamaya } \\
\text { ve yorumlamaya olanak sağlamaktadır. }\end{array}$ \\
\hline
\end{tabular}

\begin{tabular}{ll}
\hline \hline \multicolumn{1}{c}{ Assesing The Effect Of The Works Of Art History On Contemporary Artistic } \\
Designs Based On The Concepts Of Pastiche And Parody
\end{tabular}

Atıf/Citation: Vardar T. Kınık M. (2021). Sanat Tarihine Geçmiş Eserlerin, Günümüz Sanatsal Tasarımlarına Etkilerinin Pastiş ve Parodi Kavramları Çerçevesinde Değerlendirilmesi, Konya Sanat Dergisi, 4, 17-28.

"This article is licensed under a Creative Commons Attribution-NonCommercial 4.0 International License (CC BY-NC 4.0)" 


\section{GíRiş}

Sanat, insanların kendilerini ifade ettikleri, günümüzedek birçok tanıma sığdırılmaya çalışılan ancak böylelikle kapsamı gitgide genişletilen bir kavramdır. Sanat, bireyin kendisini ve çevresini tanıyıp yorumlama aracıdır. Kısaca sanat, hoşa giden biçimler yaratma çabasıdır. Yani sanatçının yaşanmış bir duyguyu içselleştirdikten sonra aynı duyguyu dinleyiciye, izleyiciye yahut okuyucuya da hissettirebilmek için hareket, çizgi, renk, ses ya da sözcükler yardımıyla yeniden canlandırdığ 1 ifade biçimidir.

Sanatın tarihine bakıldığında dönemler içinde büyük bir etkileşim gözlemlenmektedir. İnsanlık, kendinden önceki nesli doğrudan ya da dolaylı yollarla kendine ya da kendi topluluklarına mal etmiştir. Antik dönemde üretilen sanat eserleri Rönesans dönemini etkilerken, Rönesans döneminde üretilen sanat eserleri de kendinden sonra ki dönemlerde üretilen sanat eserlerini etkilemişlerdir. Postmoder süreçe kadar etkisini arttırarak devam eden alıntılama yöntemleri, sanata yeni arayış ve yorumlar getirerek anlam/kavramlar kazandırmışlardır.

Günümüz sanat eserlerinin üretiminde farklı 1rk, dil ve kültürlerin iç içe geçmişliği şüphesiz ki teknolojinin gelişmesiyle oluşmuştur. Farklı kültürlerdeki sanatçılar için bir etkileşim yöntemi olarak da ifade edilen eklektizm kavramı pastiş tekniğini desteklemektedir. Yaşanılan yer, yetiştirilme tarzı, sosyal çevre vb. unsurlar gözetmeksizin sanatın evrenselliği bu kavramlarla birlikte zenginlik kazanmaktadır.

Günümüz sanat eserleri incelendiğinde farklı kültür ve tekniklerin bir araya getirilerek yeniden üretilen sanat eserlerine yansımalarını görmekteyiz. Dünya sanatındaki başyapıtların, çeşitli alıntılama ve yorumlamalardan geçerek özgün sanat eseri olarak sunulduğu gözlemlenmektedir. Postmodernist süreçte yeniden üretilen bu özgün eserlere "melezlikle oluşan eserler" de denilebilmektedir.

Geçmişin özlemi pastiş ve parodiyi besleyerek nostaljinin abartılı yönünü gün yüzüne çıkarmaktadır. Birbiriyle alakasız ögelerin bir arada kullanılması, ilgisiz anılar, adeta bir alışkanlık çerçevesinde şekillenmektedir. Değişik kültürlerden nesneleri, kimi zaman anlamsız bir bütün oluşturacak şekilde kimi zaman da gelişigüzel yerleştirmek, mesaj kaygısı olmayan nedensiz bir bütün olarak karşımıza çıkmaktadır (İskender, 1991: 23). Pastiş ve parodi birbirinden ayrı iki tekniktir fakat birbirlerine benzerlik gösteren özelliklerine de rastlamak mümkündür. Amaçları konusunda farklılık göstermeleri, eseri taklit ettikleri tarzlarda da değişikliklere sebep olmaktadır. Parodi genel olarak alaycı ve komiktir, pastiş ise güldürü amaçlamadığı sürece ciddidir. $\mathrm{Bu}$ kavramlar günümüz sanatsal tasarımların yaratım evresinde, sanat tarihine mal olmuş eserlerin, bazen bir kesitinden bazende kompozisyon bilgisinden faydalanmaktadır.

\section{Pastiş (Öykünme)}

Çağdaş anlayışla öykünme, kopya etme sürecinden ziyade sanatçının üslubunun ya da öykünerek oluşturduğu yapıtın kendi olma özelliklerinin daha üstün olma durumudur. Direkt bir kopya olmayan ama başka bir sanat eserinden ödünç alınan tarz ve elemanlar kullanılarak yapılan sanat eseri, "başka ressamların, başka yazarların, v.b. nin üslubu taklit edilerek meydana getirilen edebiyat veya sanat eseri, benzek" olarak nitelendirilmektedir (Girgin, 2018: 39, Eczacıbaş1, 1998 ve Tuğlac1, 1971: 2291).

Benjamin, pastişin sanat öğrencileri tarafından teknik kısmı öğrenmek alıştırma yapma amacıyla kullanıldığını, sanatçılar tarafından ise eserlerin tanınırlığını artırmak için kullanıldığını öne sürmektedir (Kula, 2013: 110). Sanat eğitimi alan ve sanat ile uğraşan herkesin kendi resmetme tarzlarını oluşturabilmeleri için bir takım ön bilgilere ihtiyaçları vardır. Kompozisyon oluşturabilme, ritim ve armonik ahenk, renk bilgisi ve bu gibi sanatsal unsurları bir arada kullanabilme yetilerine sahip olmaları gerekmektedir. Tüm bu unsurlar, kişinin kendi resmetme becerisini oluşturabilmesi için gerekli alt yapıyı sağlamaktadır. Bunun yanı sıra kişi var olan bir sanat eserini bütünüyle ele alıp, kendi özgün yaratısını da 
var olan bir sanat eseri üzerinde ön plana çıkartabilmektedir. Yani öykünme bir yapıtın ortaya çıkma sürecinde tarz ve üslup konusunda destek alınabilecek bir basamak olarak da kullanılabilmektedir.

Özgün eserler üreten sanatçı; kendi üslubunu, sanatta yenilikçi yaklaşımını taklit, esinlenme, öykünme yöntemleri ile geliştirmiştir. Eski ile yeniyi bir bütün halinde ele alan pastiş(öykünme) kavramı, Rosenau'nun ifadesi ne göre pastiş; "fikirlerin ya da görüşlerin gelişi güzel, darmadağınık, kolâjı andırır biçimde bir araya gelerek oluşturdukları kırk-yamadır (patchwork). Öykünme (pastiş) eski-yeni gibi karşıt unsurları bünyesinde barındırır. Düzenliliği, mantığı ya da simetriyi yadsır; çelişki ve karşıtlıktan hoşlanır" (Emre, 2006: 156).

Özellikle de sanatçıların, eski dönem sanat eserlerinden alıntı yaparak yeniye ulaşma çabaları, bu konuda etkili bir rol oynamaktadır. Modernizm'de esinlenme, alıntı, taklit, kendine mal etme gibi kavramları düşünüldüğünde ilk akla gelen isimler: Andy Warhol, Marchal Duchamp, Pablo Picasso, Édouard Manet ve Jacques Louis David' tır. Öncellikle Jacques Louis David' en çok esinlenilen ve kendisinin de resimsel alıntıla yöntemini kullanarak kendi eserini üreten sanatçılardan biri olduğunu belirtmek gerekir. Louis David, "Marat'nın Ölümü” adlı eserini klasik idealden çok daha eskiye, Yunan ve Roma heykellerini inceleyerek, vücudun dinamik hareket yapısının nasıl hacim kazandığını ve vücudu soylu bir güzelliğe nasıl verileceğini öğrenmiştir. Antik heykellerden çizimler ve kopyalar yapan David' in Marat figürünün hareketi de daha önce işlenmiş olan “Amor ve psyche" rölyefi ve Edward Wright' in gravürü ile benzerlik taşır (Girgin, 2018: 79- 80).

Bir diğer alıntılama yöntemini eserlerinde kullanan ünlü sanatçı Pablo Picasso’ dur. Kendine has tarzıyla Velazquez'in “Nedimeler”, Francisco Goya'nın “3 Mayıs 1808”, Nicolas Poussin'in “Pan'ın Zaferi”, Eugene Delacroix’nin “Cezayirli Kadınlar”, Manet'nin “Kırda Öğle Yemeği” adlı eserleri ve buna benzer birçok eserden etkilenerek yeniden resmetmiştir. Picasso'nun eserleri, Avrupa sanat tarihinin özeti gibidir diyebiliriz. John Berger, Picasso'nun üzerine çalışacağı kendine ait bir şey olmadığını ve başka ressamların tablolarındaki temaları ele aldığını belirtmektedir. Velazquez'in "Nedimeler" adlı eserini yeniden resmettiği "Velazquez'den Sonra Nedimeler" adlı eserinde Picasso, sanatçıyı onurlandır (Berger, 2015: 195-200).

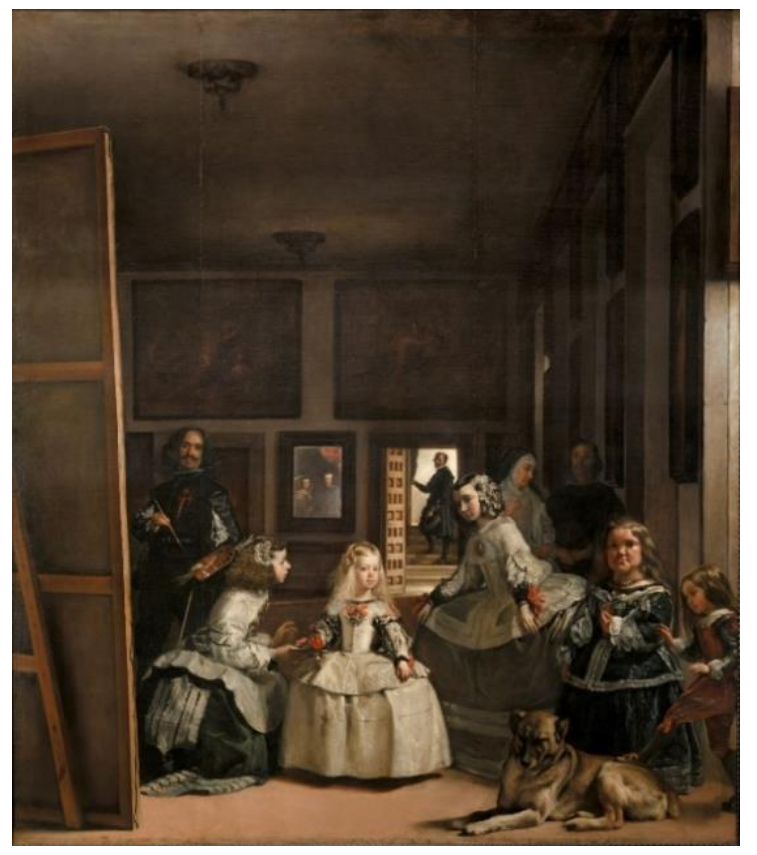

Resim 1: Velasquez, Nedimeler (Las Meninas), 1656 (URL-3)

Picasso'nun sanatçıya saygı olarak ürettiği bu eser ile Velazquez'in eseri arasında çeşitli farklılıklar bulunmaktadır. Nesnelerin boyutları ve detaylarının aktarılışında orijinalinden farklı olarak, ressamın irdelediği, beyaz elbiseli figürün resmin odağında dikkat çekici, diğer nesnelerin ise oldukça sade ve basit bir şekilde resmedildiği görülmektedir. Picasso'nun Nedimeler adlı eserini birçok kez 
resmettiği, her seferinde biçimler üzerine farklı denemeler yaptığ 1 bilinmektedir. Berger'e göre; Picasso için bunlar iki amaca hizmet etmektedir: Birincisi, ustaların yaptıklarını Picasso'nun da yapabileceğini kanitlamak, ikincisi de kültürel geleneklere verilen değerlerin ve onur payesinin abartılı olabileceğini göstermek (Berger, 2015: 111-2).

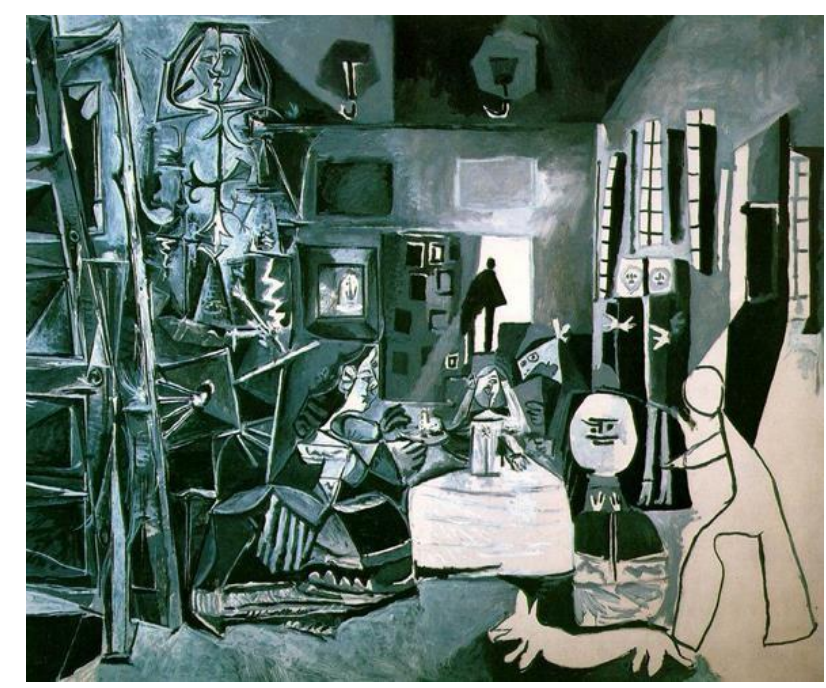

Resim 2: Pablo Picasso, Velazquez'den Sonra Nedimeler, 1957 (URL-4)

Pastiş (öykünme), postmodernist bir olgu olarak dönemin "eklektik” yapısından kaynaklı farklı sanat alanlarını kapsamaktadır. Günümüz sanat anlayışının eklektik yapısını oluşturan pastiş (öykünme), Modernizmin avant-garde kavramı ile tamamen zıt bir kavram olarak doğmuştur. Avant-garde sürekli yeniyi üretme arzusu, yerini pastişin sanat tarihine mal olan eserleri yeniden uyarlamasına bırakmaktadır (Şahin, 2015: 114).

\section{Parodi (Yansilama)}

Kelime kökeni Yunanca olan parodi; "Ciddi olduğu varsayılan bir yapıtın bir bölümünü ya da tümünü koşutlukları koruyarak alaya alan, biçimini bozmadan ona bambaşka bir içerik vererek, özle biçim arasındaki bu karşıtlıktan gülünç ve eleştirel etkiyi var etmektir” (Aktaran: Yamaner, 2007: 31) şeklinde ifade edilmektedir.

Etimolojik olarak parodi, tarihi ve sosyolojik açıdan dönemsel özellikleri de yansıtarak, daha önce ortaya çıkartılmış bir eserin, başka bir eser ile komedi etkisi yaratacak biçimde, uyumsuz bir çerçeveye konması olarak tanımlanabilir (Cebeci, 2008: 89). Parodi, bir sanatçının karakteristik tarzının taklit edilmesi ya da ödünç almanın özel bir türü olarak betimlenir. Bazı örneklerde parodi, orijinal eserden daha ünlü olabilir (Zinkhan, 1994: 3).

Parodinin içeriğindeki en önemli unsur ironidir. Bu çerçevede parodi içeren bir eser ile orijinal eser arasındaki farkı ortaya çıkaran şeyin ironi olduğu ifade edilebilir. İroni, bir şifrenin karşıt anlamlara gelecek biçimde kullanılmasıdır. Parodi ve ironi birbirlerine benzerlik gösterirler. Fakat ironi bir anlamı yadsırken, parodi bir metni yadsımaktadır. Özetle ironinin anlamsal boyutta yaptığı şeyi parodi metin boyutunda yapmaktadır (Hutcheon, 1985: 20-28). Birbirinden farklı boyutlarda üretimler yapan bu iki unsur aslında birbirini tamamlar niteliktedir ve edebi tür olarak oldukça yakın bir görünüm sergilemektedirler.

Teknolojik destekli üretim ivme kazanmış, medya yoluyla birey bilgiye ulaşma arzusunu kolaylaştırmış, bireyin sanata bakış açısı genişlemiş, alt kültür üst kültür ilişkisi ortadan kalkarak sanat artık deyim yerindeyse sokaklara inmiştir. Bu gelişmeler çerçevesinde bireyin sanatı metalaştırması da gayet doğal bir hal almıştır. İnsanların gündelik hayatta kendi düşüncelerinin bir ifadesi olan "caps" 
kültürünü de parodi yolu ile uygulayarak görsel bir ifade yolu olmuştur. Caps ifadesi 'Capture' yani yakalamak kelimesinden türetilmiştir (Url-1). Caps'in kolajlama, alıntılama ve parodi gibi kavramlarla beslenerek yeniden ürettiği görseller, günümüzün tüketim kültüründe bir popüler kültür imgesi haline gelmektedir. Postmodernist süreçte parodiden etkilenen alanların başında; resim, grafik, heykel, sinema imajları, müzik, mimari vb. gibi alanlar yer almaktadır. Sanat eserinin yüceliğini indirgeyerek geçmişe öykünen sanatçı, yeniden ürettiği sanat eserlerinin kopyalanabilir mallar kategorisine kaymasını etkin kıldı (URL-2).

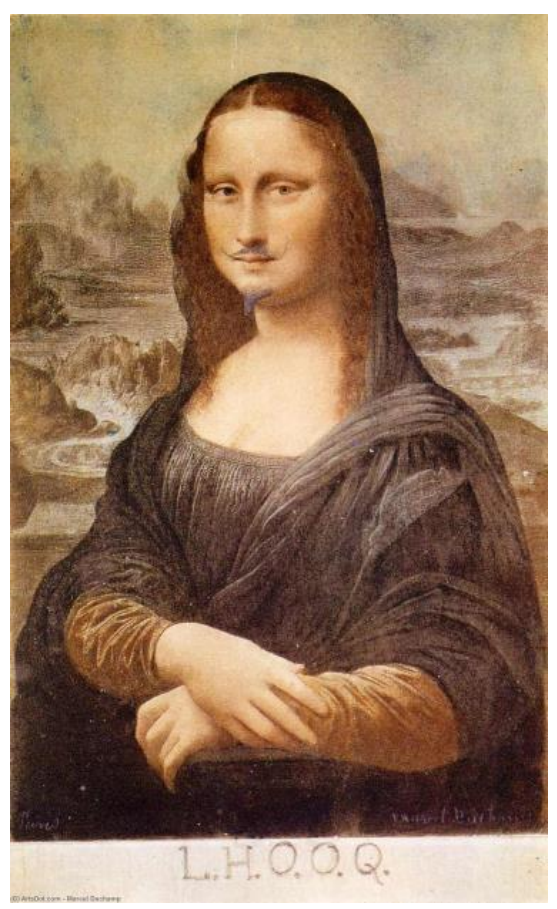

Resim 3: Marchel Duchamp, LHOOQ, (URL-5)

L.H.O.O.Q.; Marcel Duchamp'ın ilk kez 1919 yılında gösterilen, "sanat karşıtı sanat" olarak adlandırılan çalışmalarından bir örnek. Duchamp'ın Leonardo Da Vinci'nin ünlü tablosu Mona Lisa'yı alaya aldığı L.H.O.O.Q. Dadaizm akımının Avrupa'daki bir simgesi olmuştur. Sanatçı, reprodüksiyon tabloda Mona Lisa'ya bıyık ve sakal eklemiştir. Sanat tarihinde 'değer' kavramı ile ilişkilendirilen Mona Lisa eserinin üzerine uygulanan etkiler (bıyık ve sakal) bu eseri 'değersizleştirmeye' yönelik bir hareket olarak değerlendirilebilir. Uygulanan Parodi tekniği ise alaycı bir bakış göze çarpar. 
Parodi, sanat tarihine mal olan eserlerin hem etkileyici kısımlarını alır hem de yaratıcıllğı aşılamaktadır. başyapıtı mizahi eklemeler yaparak veya başka bir eserle birleştirilerek üretilen eserler özellikle Postmodernist süreçte teknolojinin gelişmesi ve hızla ilerlemesi, dünya nüfusunun büyük bir çoğunluğunun teknolojik materyallere olan ilgisini arttırmaktadır. Bu ilgi artışı kişilerin geleneklere bakış açısını değiştirmiş, tabularını yıkarak ulaşılamayan nesneleri ulaşılabilir kılmıştır.

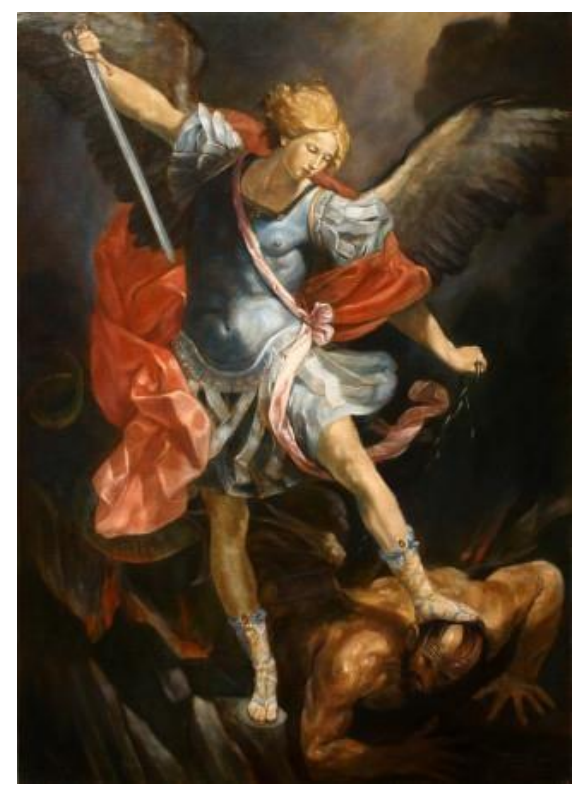

Resim 4: Guido Reni, Archangel Michael, 1635 (URL-6)

Reni’nin eseri incelendiğinde göze ilk çarpan, korkunç ve şiddetli bir mücadelenin sonuna gelmiş iki figür görülmektedir. Ölümcül darbe öncesi zafer duruşu sergileyen Michael, büyük mücadele sonunda kazandığını ilan eder gibi resmedilmiştir. İyilik ve kötülük, karanlık ve 1şık arasındaki bir savaşın sonunu getiren Michael ve düşmüş olan bir ruh sembolize edilmiştir. Baş melek Mikail tarafindan boyun eğdirilerek, ayağı ile kafasına bastırılmıştır. Michael'in ayağının kenarına yansıtılan ışık, şeytanın yüzündeki mağlubiyeti direk ezici bir güçle göstermektedir. Michael'ı süsleyen kıyafet, bir Romalı askerin tarzında resmedilmiştir. Askerlerin itibarının ne kadar yüce olduğu da bu karede gösterilmektedir (Wikiart: 2019). Kılıcı, tereddüt ve tehdit olarak algılanıyor, belki de kötü yaratı̆̆ın nasıl yenileceğine dair seçeneklerini tartmaktadır. Yaşamak mı yoksa ölmek mi? Arka plan, iki figür arasındaki savaş kadar karışık, dönen bulutlar ve alevler savaşın ne kadar zorlu geçtiğinin bir yansıması olabilir. Bu etkili ve güçlü çalışmayı yaratan sanatçı Guido Reni, doğaya ait nesneleri resmetme konusunda uzmanlaşmıştır.

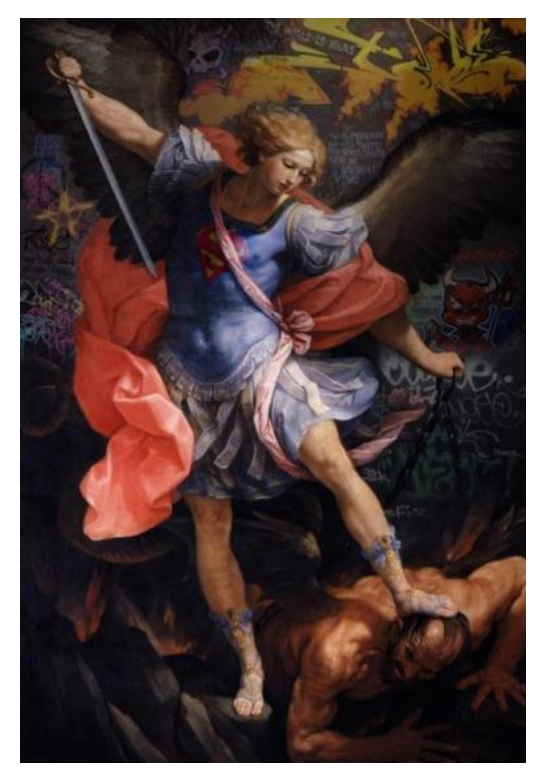

Resim 5: Marco Battaglini, Concussus Surgo, 2015 (URL-7) 
Battaglini tarafından parodi yolu ile üretilen bu eser, baş melek Michael' in kutsallığını bir popüler kültür imgesi ile yorumlanmaktadır. Postmodern sürecin bir ifadesi olan, gücü ve kurtarıcı rolünü üstlenen sinema karakterini bir yansılama yaparak yeniden resmetmiştir. Arka planda yer alan grafitiler, günümüz duvar resimlerine gönderme yaparak resmedilmiştir. İzleyicinin ilk bakışta fark edemediği dövmeler Michael'in kudretini vurgulamaktadır.

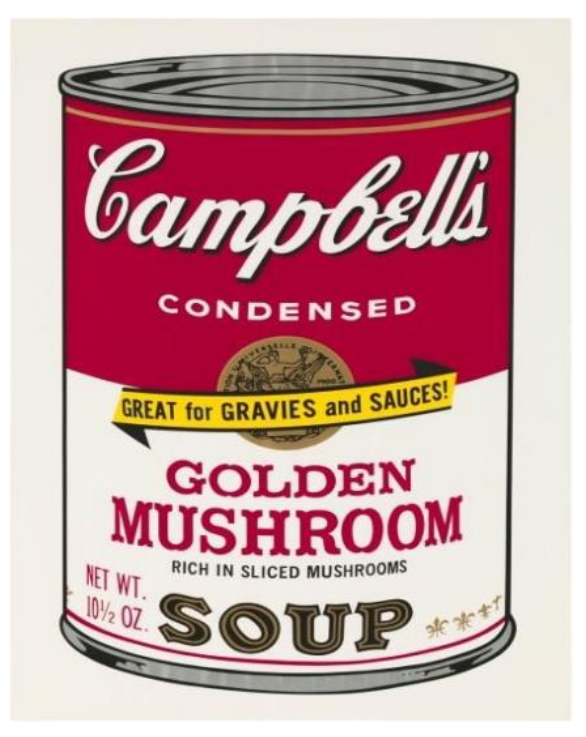

Resim 6: Andy Warhol, 32 Campbell's Soup Cans, 1962, (URL-8)

“Campbell çorba tenekelerini” serigrafi_baskı tekniği kullanarak yeniden üreten sanatçı, ürünün sıradan olan, çokça tüketilen, kolayca bulunan ve herkes tarafından bilinen, günlük tüketim nesnesinden çıkarıp bir postmodern sanat anlayışı ile bir sanat eserine dönüştürmüştür. Sanat hayatının büyük bir bölümünü popüler kültürden esinlenerek eserler üreten sanatçı, tüketim kültürünün sanat ile iç içe geçmesine katkı sağlamıştır (Moma: 2019).

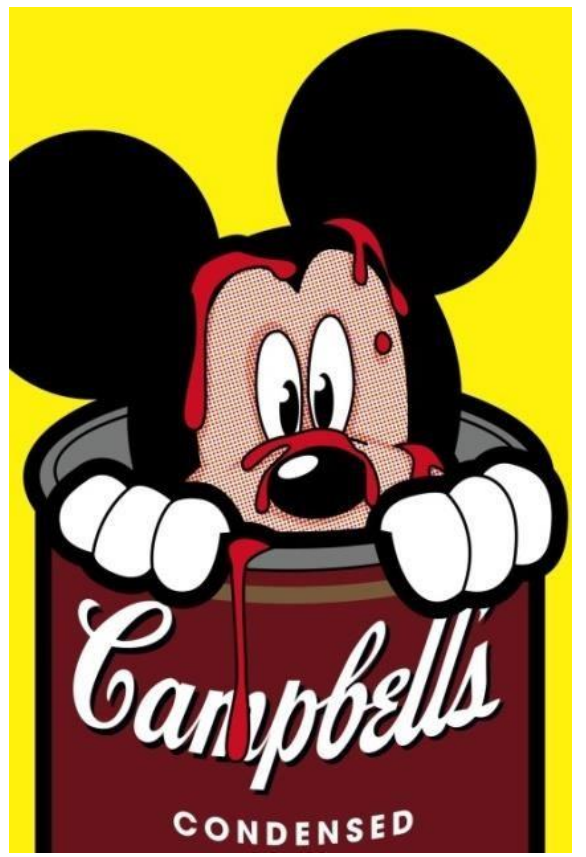

Resim 7: Greg Guillemin, Mickey Mouse and Andy Warholl, 2011 (URL-9) 
Andy Warholl'un "Campbell's Tomato Soup" adlı eserinin ifadesi, sanat eseri olarak yüceltilen eserlere ve yüksek sanat kavramının oluşturduğu anlamlar bütününe meydan okumak olarak adlandırılabilir. Seri halde üretilen, kolayca bulunan ve herkes tarafindan kullanılan bir konserve kutusunu alıntı yaparak yeniden üreten sanatçı, bu tavrı ile izleyiciyi düşünsel bakımdan zorlayıp, "Tüketim nesnesini sanat eseri yapan nedir?" sorusunu düşünmeye sevketmek istemiştir. Guillemin'ın bu eseri parodi olarak yorumlanabilir. Televizyon dünyasının ünlü çizgi roman kahramanını Warholl'un eseriyle bütünleştiren sanatçı iki farklı alandaki sanat eserini birleştirerek_yeniden üretmiştir. Üretilen eser pastiş yoluyla başladıysa da parodiye dönüştürülmüştür. Eserde teneke kutunun içinde yer alan Mickey (Xxx Devletleri' nin xxx popüler kültür imgesi), kurnaz bir şekilde resmedilmiştir. Guillemin'ın resminin genel bir ifade yolu olan gösterişli renkler, bu eserin de arka planında yer almaktadır.

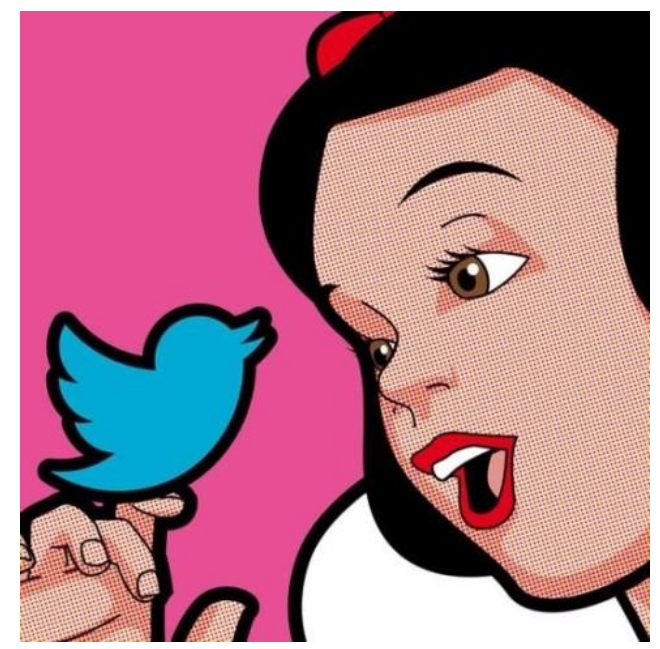

Resim 8: Greg Guillemin, Pop Icon - Snow Tweet, 2011 (URL-10)

Greg Guillemin, 1967 doğumlu bir Fransız ressamdır. Kendisini içine sokmayı sevdiği halk kültürü kahramanlarının yer aldığı "Secret of the Heroes" adlı eserleri dizisinde başarılı postmodern işler üretmiştir. Klasik dönemde üretilen sanat eserleri ile günümüz popüler kültür imgelerini birleştirerek yeniden üretim yapan bir sanatçıdır (Sanal: 2019). Fransız sanatçı, popüler kültür öğelerinin bilinmeyen hayatları olduğuna dair bir felsefe taşıyan çalışmalarında dijital teknolojiyi terk etmeden, akrilik malzeme ile deneysel işler meydana getirmektedir. Guillemin'ın eserlerinde kullandığı, çizgi romanlarda ve çizgi filmlerde de yer alan karakterlerin özel hayatlarına işaret ettiği söylenebilir.

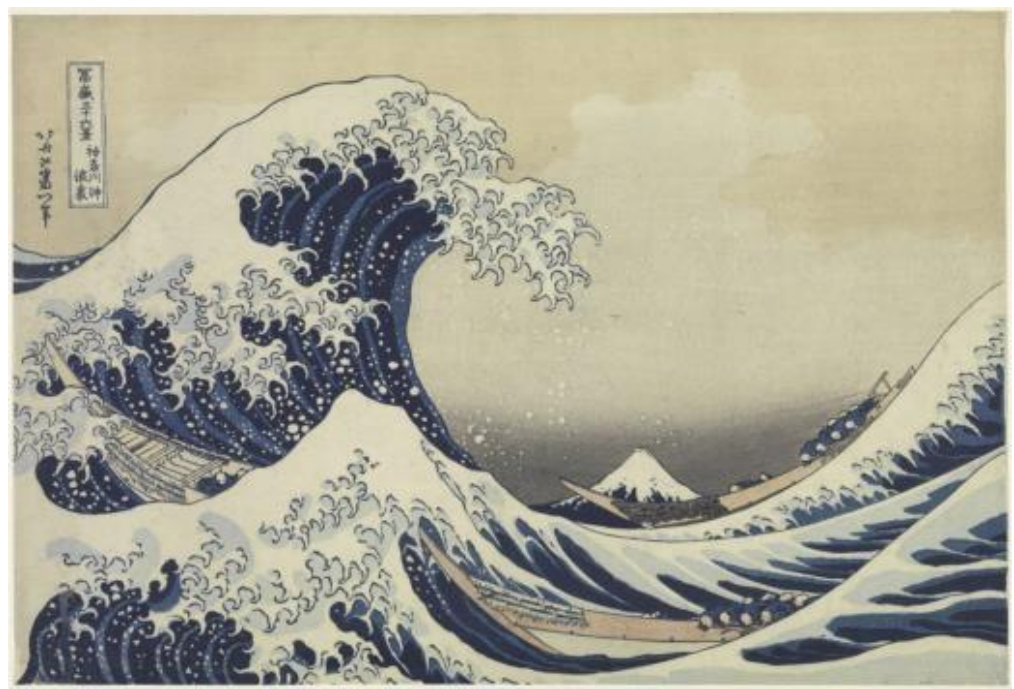

Resim 9: Katsushika Hokusai, The Great Wave of Kanagawa, 1829-1832 (URL-11) 
The Great Wave of Kanagawa, Japon ukiyo-e ustası Katsushika Hokusai'nin tanınmış tahta baskı eseridir. Eser ilk olarak 1832'de Fuji Dağı manzarasının bir parçası olarak basılmış ve aynı serinin en çok tanınan eserlerinden biri olmuştur. Katsushika Hokusai'nin "Büyük Dalga" olarak da adlandırılan "Kanagawa'daki Dalga Altında" isimli eseri, dünyanın en ünlü sanat eserlerinden biri haline gelmiş ve kuşkusuz Japon sanatının en ikonik eseri olmuştur. (Wikipedia, 2019).

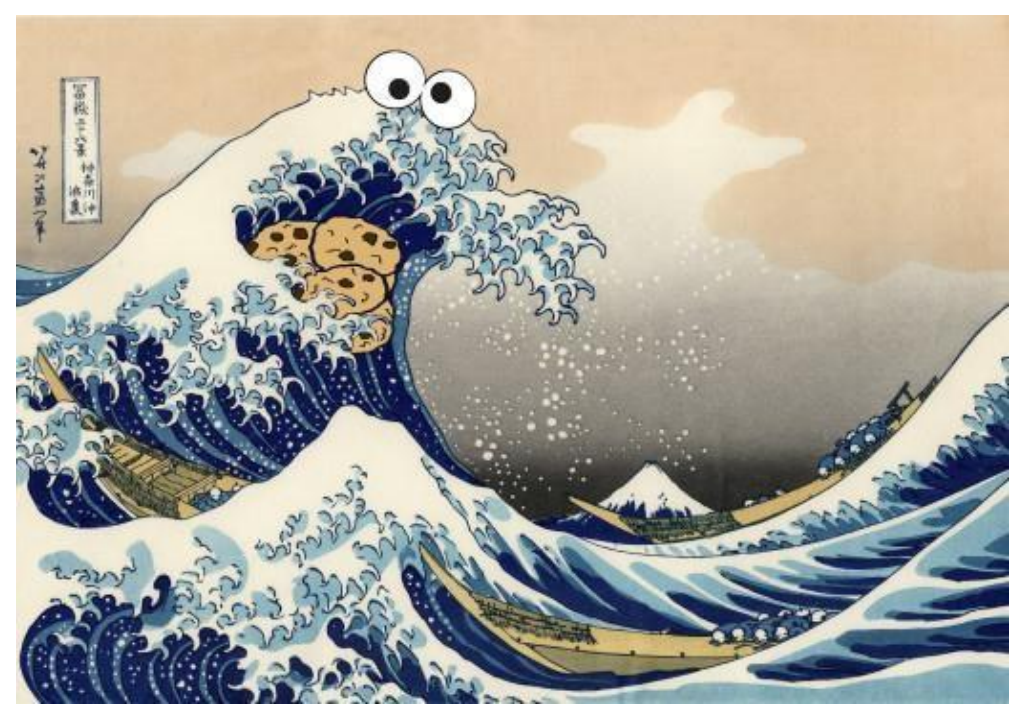

Resim 10: Sonny Malhotra, Sea is for Cookie, 2013 (URL-12)

Malthora, 2013 yılında Hokusai'nin eserini yeniden yorumlamıştır. Dalga imgesini Kurabiye Canavarı adlı karaktere dönüştürmüş ve günümüz animasyonunda yer etmiş bir Muppet ile ünlü Japon sanatçının döneminde ses getirmiş bir eserini alaycı bir tasvir ile yansılamıştır.

Pastiş ve Parodi arasındaki en belirgin ayrımı şu şekilde değerlendiren Karadoğan; resim sanatının yeni bir ifade yolu olan pastiş; diğer yapıtların imgelerini ve bölümlerini kısım kısım alarak uygularken, onları yeniden üretmekte ve parçalara giderek daha canlı bir etki bırakmaya çalışmaktadır. Geçmişte ve günümüzde de yer alan ve etkili olan biçemleri gözden düşürmeyi ve onlarla alay etmeyi amaçlayan parodi ise, günümüz sanat anlayışı içerisinde verimli bir yaşam alanı bulmaktadır (Karadoğan, 2005: 147). Pastiş ve parodi birbirinden ayrı iki tekniktir fakat birbirlerinden ayırıcı özellikleri olduğu gibi benzerlik gösteren özelliklerine de rastlamak mümkündür. Postmodern sanatçı, kendisine yeni bir ütopya oluştururken daha önceki eserlerin evreninde gezinmekte ve kendi yaratısı için veriler toplamaktadır. Sanatçı, orijinal eserlerden bazen postür, bazen imge ya da motif, bazen de kompozisyon tekniği olarak etkilenirken yaratısını pastiş ve parodi düzleminde kurmaktadır. Bu anlayışa göre öykünülen ya da yansılanan her yeni eser orijinalinden etkilenmektedir. Pastiş (öykünme) ve parodi (yansılama) işlemleri metinlerarasılık olarak ifade edilen kavramlardır. Teknik olarak birbirlerine benzeyen bu iki işlem amaçladıkları konular açısından farklılık göstermektedir.

\section{SONUÇ}

Geçmişten günümüze kadar oluşan sanat anlayışına bakıldığında, sanatçılar kendilerinden önceki sanatçı ve eserlerini örnek alarak yeni eserler üretmiş, yenilikçi yaklaşımlarda bulunmuşlardır. Postmodernist bir strateji olarak sanat tarihinde yer alan pastiş ve parodi günümüz sanatında da sıkça kullanılan yöntemler arasında yer almaktadır. Pastiş sadece postmodern zamanın içerisinde yer alan bir kavram olmamıştır. Modernizm ve öncesine bakıldığında birçok sanatçı ve eserin bir etkileşim içerisinde olduğunu söylemek mümkündür. O halde parodinin eklektik yapısının pastişten etkilendiği ifade edilebilir.

Teknolojinin belirleyici bir rol üstlendiği günümüz sanatında, sanatçıların da başka yapıtlardan etkilenmesi yadsınamaz bir gerçektir. Farklı dönemdeki farklı sanatçıların eserleri günümüz sanatında 
bir bütün olarak işlenmiş, alıntılanarak kolajlanmıştır. Sanat tarihine mal olmuş bu eserleri yeniden üreten sanatçı yergi ya da yüceltme amacı güderek kendisine mal etmektedir. Sanatın bu denli değişim ve dönüşüme uğramasının başlıca sebepleri toplumsal olaylar olmuştur. Doğanın taklidini oluşturarak gerçeklik sunmaya çalışan sanatçılar teknolojinin gelişmesi ile birlikte doğayı taklitten uzaklaşarak iç dünyalarına yönelmişlerdir. Sanatçi için en sıradan olan nesnenin bile bir sanat eseri olabileceği ifade edilmiştir.

Her bir alanda öykünülen sanat eserlerinin içeriği değiştirilmiş ve farklı bir sentezle yorumlanmıştır. Bu bağlamda, kimi zaman pastiş yolu ile geçmişte üretilen eseri yücelterek tekrar günümüze taşıyan sanatçı, kimi zaman da parodi yolu ile mizahi bir üretim yaparak geçmişi yaşatmışlardır. Bu çalışmada, Sanat tarihine mal olmuş eserlerin, pastiş ve parodi kavramları çerçevesinde günümüz sanatına nasıl yansıdığı örneklerle açıklanmıştır.

\section{KAYNAKLAR}

Berger, J. (2015). Picasso ’nun Başarısı ve Başarısızlı̆̆ı. 6. Baskı, Metis Yayınları, İstanbul.

Cebeci, O. (2008). Tarihsel Bir Perspektif Üzerinden İroni Tür ve Tekniklerinin Gelişimi ve Bazı Uygulama Örnekleri, Cogito Dergisi: Ironi, 57. Sayı: s.87-184.

Emre, İ. (2005). Postmodernizm ve Edebiyat. An1 Yayınları, Ankara.

Girgin, F. (2018). Çağdaş Sanat ve Yeniden Üretim, 1. Baskı, Hayalperest Yayınevi, İstanbul.

Hutcheon, L. (1985). A Theory of Parody: The Teachings of Twentieth Century Art Forms. Methuen Publishing, New York.

İskender, K. (1991). Klasisizmin Post-Modern Dönemi ve Post- Modernizmin Klasisizmi, Sanat Çevresi Dergisi, 155. Sayı, Eylül 1991.

Karadoğan, A. (2005). Postmodern Sinema Mı Film Mi ?, Illetişim: Araştırmaları Dergisi, 3. Sayı, (1-2): 133-160.

Kula, OB. (2013). Marx, Benjamin, Adorno Sanat Ve Edebiyat. 1. Baskı, Türkiye İş Bankası Yayınları, İstanbul.

Rose, AM. (2016). Parodi: Antik, Modern ve Postmodern (Çev. Cansu Dikme), 1. Baskı, Hece Yayınlar1, Ankara.

Şahin, H. (2015). Günümüz Sanatında Üslup Karmaşası ve Pastiş, Art-e Sanat Dergisi, 15. Sayı, s.11026.

Tuğrac1, P. (1971). Okyanus Türkçe Sözlük, 2. Cilt, Pars Yayınevi, İstanbul.

Yamaner, G. (2007). Postmodernizm ve Sanat. 1. Bask1, Alg1 Yayın, Ankara.

Zinkhan, GM. (Ed.) (1994). The Use Of Parody in Advertising, Journal of Advertising.

URL-1: Sabah Gazetesi, “Caps Ne Demek?”, https://www.sabah.com.tr/caps-ne-demek, (Erişim Tarihi: 08.05.2019)

URL-2: Moulın, R. (Çev. Ayşe Boren, Elçin Gen); Teknik Olarak Kopyalanabildiği Çağda Sanat Eserinde Benzersizliğin Üretimi, http://www.e- skop.com/skopbulten/teknik-olarakkopyalanabildigi-cagda-sanat-eserinde- benzersizligin-uretimi/3104, (Erişim Tarihi: 08.05.2019)

URL-3: Resim:1(2019), Velasquez, Nedimeler (Las Meninas), 1656 https://www.sanatabasla.com/2012/07/24/nedimeler-las-meninas-velazquez/ (Erişim Tarihi: 03.04.2019)

URL-4: Resim:2(2019), Pablo Picasso, Velazquez'den Sonra Nedimeler, 1957 https://ipfs.io/ipfs/QmT5NvUtoM5nWFfrQdVrFtvGfKFmG7AHE8P34isapy

hCxX/wiki/Nedimeler_(tablo).html (Erişim Tarihi: 03.04.2019)

URL- 5: Resim: 3(2019), https://www.haberturk.com/marchel-duchampin-biyikli- mona-lisatablosu-lhooq-satista-1683450 (Erişim Tarihi: 15.07.2019)

URL-6: Resim: 4(2019), Guido Reni, Archangel Michael, 1635 https://tr.pinterest.com/pin/545568942343059929/?lp=true (Erişim Tarihi: 16.04.2019)

URL-7: Resim: 5(2019), Marco Battaglini, Concussus Surgo, 2015 https://tr.pinterest.com/leftlanecreatives/weird-art-eclectic-artistic-works/ (Erişim Tarihi: 17.04.2019)
URL-8:
Resim:
6(2019),
Andy
Warhol,
Campbell's
Soup Cans 
Sanat Tarihine Geçmiş Eserlerin, Günüimüz Sanatsal Tasarımlarına Etkilerinin Pastiş...

https://www.moma.org/learn/moma_learning/andy-warhol-campbells-soup-cans-1962/, （Erişim

Tarihi:21.04.2019)

URL-9: Resim: 7(2019), Greg Guillemin, Mickey Mouse and Andy Warholl, 2011 https://tr.pinterest.com/texasdiva74/oh-mickey/ (Erişim Tarihi: 21.04.2019)

URL-10: Resim: 8(2019), Greg Guillemin, Pop Icon - Snow Tweet, 2011 https://twitter.com/Greg_Guillemin/status/717067822287953920 (Erişim Tarihi: 20.04.2019)

URL-11: Resim: 9(2019), Katsushika Hokusai, The Great Wave of Kanagawa, 1829-1832 https://pixers.com.tr/duvar-resimleri/japonya-dalga-34057734 (Erişim Tarihi: 22.04.2019)

URL-12: Resim: 10(2019), Sonny Malhotra, Sea is for Cookie, 2013 https://tr.pinterest.com/pin/78672324722265782/?lp=true (Erişim Tarihi: 22.04.2019) 


\section{EXTENDED ABSTRACT}

Art history is a series of interactions that have been approaching since life. Humanity is a choice of its own or of its own communities. The products in the antique production facilities influenced the Renaissance, the art products and designs of the periods after the Renaissance design designs.

In today's art, the development of technology has made communication even more powerful. The simultaneous spread of artistic designs and images to the world increased interaction and contributed to the development of pastiche and parody. Pastiche (emulation) is called a method that takes place in the formation phase of the work of art. Another method in the postmodern period is Parody (reflection). While the works produced by pastiche are respectful to the artist, the works produced by parody display a cynical and humorous attitude. The pastiche, which shows respect to the artist and the work of art, has given birth to the parody, which is the opposite of itself. When today's works of art are examined, we see the reflections of different cultures and techniques on art works that are reproduced by combining them. It is observed that the masterpieces of world art are presented as original works of art by going through various quotations and interpretations. These original works, which are reproduced in the postmodernist process, can also be called "works formed by hybridity". Pastiche and parody are two different techniques, but it is possible to come across features that are similar to each other. The fact that they differ in their purpose also causes changes in the styles in which they imitate the work. Parody is generally sarcastic and funny, while pastiche is serious unless it is intended for comedy. These concepts, in the creation phase of today's artistic designs, benefit from sometimes a cross section and sometimes composition knowledge of works that have cost art history. In this article, contemporary works of art, which refer to themselves by using citation methods such as pastiche and parody, are examined with examples. In this research, a wide literature review was applied as a result of researches on domestic and foreign sources in order to investigate the effects of the concepts of pastiche and parody on today's artistic designs. Documentary source compilation technique was preferred in the research. In addition to the sources related to the subject, side sources that will feed the subject were researched, acquired and examined. In the preparation of the study, visual and literary sources such as books, articles, magazines, encyclopedias, newspapers, libraries, interactive links, photographs were searched on the basis of the scanning method and tried to be expressed in terms of conceptual and literary.

How are these citation methods, works, images and ideas that have been collected under the headings such as parody and pastiche, and how are they criticized, criticized or praised by today's artists, and how are they positioned? In this context, how was the pastiche handled in order to produce new works in the art of painting?

When considered as a form of pastiche and parody, which are the defining elements of postmodern teaching, it is used as a method of citation in branches of art. The artists who produced the work inspired the artists after them and gave them a perspective. These methods, which bring meaning/concepts to art by bringing new searches and interpretations, mostly appear in the postmodern period and allow us to understand and interpret the reproduced works. Undoubtedly, the factor in the formation of the mentality of the artist in the postmodern period, based on the synthesisist understanding, is the use of technology in the field of art. The development of simulation has moved the work of art out of museums and into everyday living spaces. Even if the audience has never seen the original work, they can have an idea about the work through the media. One of the most effective ways that today's artists benefit from in the production phase is reproduction using technology. Today's artist has changed the course of art by integrating a work of art produced in the past with consumption objects in daily life and bringing it together with the audience. Pastiche and parody concepts are used in many areas of art. It has been inevitable to come across parody examples especially in the art of cinema. These two techniques, which we encounter in many other branches of art, have consciously or unconsciously placed in our minds in today's technology age. It is common to encounter these two concepts in social media or advertising content. However, although parody is more memorable due to its humorous basis, it is not known whether it is a technique and for what purpose it is used. Pastiche samples, on the other hand, cannot be distinguished from the original, even if they have different purposes, due to the fact that they have a structure that hovers around the original. 